\title{
CRESCIMENTO DA PLANTA E COLORAÇÃO DAS RAÍZES COM HEMATOXILINA COMO CRITÉRIOS DE AVALIAÇÃO DE GENÓTIPOS DE CAFÉ QUANTO À TOLERÂNCIA À TOXIDEZ DE ALUMÍNIO(1)
}

\author{
M. C. L. BRACCINI (2), H. E. P. MARTINEZ(3), E. A. M. SILVA(4), \\ A. L. BRACCINI ${ }^{(5)} \&$ C. A. SCAPIM(5)
}

\begin{abstract}
RESUMO
A seleção de plantas tolerantes ao Al é uma alternativa para solos que apresentam Al em níveis tóxi cos. Neste contexto, vinte e cinco genótipos de café foram estudados quanto à tolerância ao Al avaliada pela inibição no cresci mento da parte áer ea e das raízes e pelo teste de coloração das raízes com hematoxilina. Avaliou-se, também, a alocação do Al nas pontas das raízes. Após 35 e 75 dias de cultivo em solução nutritiva, na ausência ou presença de Al, foram avaliados o comprimento da raiz principal e, aos $\mathbf{8 0}$ dias, a produção de biomassa seca da parte aérea e das raízes. Os resultados expressos em percentagem de ini bição causada pelo Al foram analisados pela técnica multivariada, e os genótipos foram separados em classes: tolerante, intermediária e sensível. 0 teste de coloração com hematoxi lina foi realizado após $\mathbf{8 0}$ dias de cultivo em solução nutritiva, e os genótipos foram avaliados de acordo com a intensidade de coloração da ponta da raiz. Apenas três genótipos foram tolerantes ao Al e seis foram sensíveis, enquanto a maioria deles pertenceu à classe de tolerância intermediária. 0 teste de coloração com hematoxilina não permitiu a adequada diferenciação dos genótipos quanto à tolerância ao alumínio. E m cortes transversais das pontas das raízes do genótipo mais tolerante, observou-se a localização do alumínio apenas nas células epidérmicas, enquanto, no genóti po de tolerância intermediária, o Al localizou-se nas células epidérmicas e em várias camadas de células do córtex.
\end{abstract}

Termos de indexação: Coffea arabica L., C. canephora Pierre, seleção, estresse, solos ácidos.

\footnotetext{
(1) Parte da Tese de Doutorado do primeiro autor, apresentada à U niversidade Federal de Viçosa. Realizado com auxílio do CNPq e da FAPEMIG. Recebido para publicação em janeiro de 1999 e aprovado em janeiro de 2000.

(2) Estudante de Doutorado do Departamento de Fitotecnia da Universidade F ederal de Viçosa, CEP 36571-000 Viçosa (MG). Bolsista do CNPq. E-mail: albraccini@uol.com.br

(3) Professor Adjunto do Departamento de Fitotecnia - UFV. Bolsista do CNPq.

(4) Professor Titular do Departamento de Biologia Vegetal - UFV. Bolsista do CNPq.

(5) Professor Adjunto do Departamento de Agronomia da Universidade Estadual de Maringá (UEM). Av. Colombo, 5.790. CEP 87020900 Maringá (PR). Bolsista do CNPq.
} 


\title{
SUMMARY: PLANT GROWTH AND ROOT HEMATOXYLIN STAINING TO EVALUATE ALUMINUM TOXICITY TOLERANCE OF COFFEE GENOTYPES
}

\begin{abstract}
The screning of plants for aluminum tolerance is an alternative to soils with toxic levels of this el ement. Twenty five coffee genotypes were evaluated for al uminum tol erance in relation to inhibition of shoot and root growth and by the hematoxyl in staining test. The al uminum accumulation in root tissues was al so evaluated. After 35 and 75 days of plant growth in nutrient solution with and without al uminum, the length of the main root was evaluated. After 80 days of exposure to Al, the dry biomass of shoot and roots was also evaluated. The inhibition percentage promoted by aluminum was analyzed by the multivariate technique and the genotypes were classified as tolerant, intermediate and susceptible. Thehematoxylin staining test was conducted after 80 days of plant devel opment in nutrient solution and the genotypes were eval uated by theintensity of root tip staining. Theresults indicated that only three genotypes were classified as Al tolerant, and six were susceptible, while most of the genotypes were in the intermediate class. The hematoxylin staining test was not suitable for assessment of Al tolerance. The Al accumulation in the most tolerant genotype was only observed in the epidermal cells, while in the genotypes classified as intermediate, therewas Al accumulation in theepidermal cells and in several layers of the cortex cells.
\end{abstract}

Index terms: Coffea arabica L., C. canephora Pierre, screening technique, stress, acid soils.

\section{INTRODUÇÃO}

A presença de Al em níveis tóxicos nas camadas subsuperficiais pode limitar o crescimento e desenvol vimento do sistema radicular das plantas, tornando-as menos tol erantes às condições de déficit hídrico.

O problema toxidez de Al e deficiência de Ca no subsolo pode ser contornado ou reduzido de várias formas, seja pelo movimento do Ca aplicado na camada arável (Chaves et al., 1988; Guimarães, 1992), seja pelo uso de cultivares tol erantes (Taylor, 1991). Em muitos solos, a calagem aplicada na superfície causa pouca movimentação de $\mathrm{Ca}$ e el evação do pH para neutralizar o Al no subsolo (Chaves et al., 1988). Recomendam-se, como alternativas, a correção superficial do solo, como usual mente é feita, e a utilização de variedades com capacidade de emitir raízes em subsolos com Al em níveis tóxicos (Taylor, 1991; Foy, 1997).

$\mathrm{Na}$ caracterização de genótipos tolerantes a Al, existem diferentes procedimentos de "screening" que podem ser divididos em quatro categorias: (a) avaliações, em solução nutritiva, do crescimento da parte aérea e do sistema radicular, na presença e na ausência de Al (Wallace et al., 1982; Cambraia et al., 1991); (b) cultivo em solo com diferentes saturações por Al (F oy, 1997); (c) testes de coloração que avaliam o acúmulo de Al na extremidade das raízes, como hematoxilina, pyrocatechol e nitrato de prata (Massot et al., 1991; Rincón \& Gonzales, 1992; Braccini et al., 1996), e (d) cultura detecidos e células (Mix, 1990).
Estudos realizados em solução nutritiva apresentam uma série de vantagens, por permitirem comparar grande número de genótipos em menor espaço de tempo e controlar fatores associados à toxidez, como pH e composição da solução. Além disso, possibilitam a utilização das plantas após a avaliação dos efeitos tóxicos do $\mathrm{Al}$, que é um ponto extremamente importante no caso decultura perene, como o café, que apresenta taxa de crescimento muito lenta.

A técnica de coloração com hematoxilina tem sido usada para sel ecionar cultivares de trigo tolerantes ao Al (Polle et al., 1978; Wallace et al., 1982). O método é simples e se baseia na propriedade da hematoxilina de apresentar col oração violeta, quando complexada com Al, permitindo detectar o acúmulo de $\mathrm{Al}$ nos tecidos radiculares.

Para as diferentes técnicas de seleção existem, na literatura, vários critérios para avaliar a tolerância. Os mais fáceis são baseados em observações visuais da evolução de necrose na parte aérea enosistema radicular (Nuernberg et al., 1990). São, também, muito utilizadas as medidas de produção de biomassa seca da parte aérea e das raízes, comprimento total ou comprimento da raiz principal, volume e número de raízes, redução relativa na elongação radicular, capacidade de recuperação das plantas após a remoção do estresse de $\mathrm{Al}$ e índice de tolerância [(crescimento com Al/ crescimento sem Al) * 100] (Wallace et al., 1982; Cambraia et al., 1991). Entretanto, não existe consenso entre os pesquisadores para propor condições experimentais e critérios para avaliar a 
sensibilidade ao Al. Nuernberg et al. (1990) verificaram que na classificação de cultivares de trevo vermelho quanto à tolerância ao Al, a combinação de duas ou mais variáveis, especialmente aquelas envolvendo parte aérea e raízes, apresenta resultados mais consistentes.

Braccini et al. (1998) avaliaram a contribuição relativa de diferentes características de crescimento, por meio da técnica multivariada de análise de componentes principais, para discriminar nove genótipos de café quanto à tolerância ao alumínio, cultivados em solução nutritiva. As características radiculares - redução do peso de matéria seca de raiz e do comprimento da raiz principal e aumento do número de raízes secundárias - foram as que mais contribuíram para discriminação dos genótipos. As características de menor importância foram: peso de matéria seca total, área foliar, peso de matéria seca da parte aérea e altura de planta.

O objetivo deste trabal ho foi selecionar genótipos de café quanto à tolerância ao alumínio, em decorrência da inibição no crescimento das plantas e da coloração das raízes com hematoxilina, bem como avaliar a alocação do alumínio em cortes de extremidade de raízes.

\section{MATE RIAL E MÉTODOS}

\section{Inibição no crescimento da parte aérea e das raízes e na elongação radicular}

Sementes de vinte e cinco genóti pos de café, sem o pergaminho, foram colocadas para germinar em rolos de papel-toalha à temperatura de $30^{\circ} \mathrm{C}$. Após 40 dias, as plântulas foram transferidas para casa de vegetação. Após a sel eção, quantoà uniformidade de tamanho, as plântulas foram fixadas em placas de isopor, revestidas com papel alumínio, ecol ocadas em bandejas com 13 litros de solução nutritiva. Utilizou-se a solução de Hoagland \& Arnon (1950) diluída a $1 / 4$ e modificada quanto à concentração de P $(0,025 \mathrm{mmol} \mathrm{L-1})$. O alumínio foi fornecido nas concentrações de 0 e 0,296 mmol L-1, como $\mathrm{AlCl}_{3}$. A concentração de fósforo e o pH da solução nutritiva foram mantidos baixos para minimizar a precipitação com alumínio. O pH das soluções foi ajustado diariamente com $\mathrm{HCl} 0,1 \mathrm{~mol} \mathrm{~L}^{-1}$ ou $\mathrm{NaOH}$ $0,1 \mathrm{~mol} \mathrm{~L}^{-1}$ para 4,2 , permitindo variações de $\mathrm{pH}$ entre 4,0 e 4,4, durante o período experimental de 80 dias. As soluções foram mantidas sob arejamento constantee as trocas foram realizadas a cada 30 dias.

O delineamento experimental utilizado foi em blocos casualizados com quatro repetições, num esquema fatorial com 50 tratamentos, constituídos pela combinação de 25 genótipos (Quadro 1) e dois níveis de alumínio. A parcela experimental foi constituída de três plantas.
Avaliou-se o comprimento da raiz principal aos 35 e 75 dias, para calcular sua taxa de crescimento e a redução relativa na elongação radicular (REDREL), neste intervalo de tempo, determinada da seguinteforma: $\{1$ - (incremento com Al/incremento sem Al)] x 100\}. Aos 80 dias, foram col hidas a parte aérea e as raízes. Após a secagem em estufa de circulação for çada de ar, à temperatura de $70^{\circ} \mathrm{C}$ por 72 h, foi avaliada a produção de biomassa seca da parte aérea e das raízes.

Para identificar os genóti pos quanto à tolerância ao $\mathrm{Al}$, os percentuais de redução no crescimento da parte aérea e das raízes $\{\% R C=[1$ - (crescimento com Al/crescimento sem Al)] x 100\} e na el ongação radicular (REDREL) foram analisados pela técnica multivariada baseada na função discriminante, proposta por Anderson (1958). Esta técnica é usada para separar grupos de observações distintos ealocar nova observação em grupo previamente definido. Funções lineares são cal culadas para os dados de grupos com o propósito de classificar novo indivíduo em um dos grupos. Esta análise pressupõe uma otimização da classificação quando se considera, simultaneamente, um conjunto de variáveis tomadas em cada genótipo.

Para obtenção das funções discriminantes, é necessário o conhecimento prévio dos genótipos que pertencem a cada um dos grupos em que se pretende alocar os materiais genéticos de comportamento desconhecido. Tomando como referência experimento preliminar, o genótipo UFV 2955 foi utilizado como padrão representativo de tolerância, os genótipos UFV 2145 e 2164, como padrão de tolerância intermediária, e UFV 2877 e 3880, como padrão de sensibilidade.

Pel o critério de classificação de Anderson (1958), determinado genóti po é considerado tolerante, se o resultado da função discriminante $D_{t}(x)$ for maior que $D_{i}(x)$ ou $D_{s}(x)$; de tolerância intermediária, se $D_{i}(x)$ for maior que $D_{t}(x)$ ou $D_{s}(x)$, esensível, em caso contrário. $\mathrm{Na}$ análise discriminante, utilizou-se o programa GENES I - Análise demodel os biométricos aplicados ao mel horamento genético (Cruz, 1997).

\section{Teste de coloração das raízes com hematoxilina e alocação do alumínio nos tecidos radiculares}

As plântulas foram mantidas em solução nutritiva deH oagland \& Arnon (1950), diluída a 1/4 a pH 6,0, por um período de 80 dias, na ausência de alumínio. Em seguida, foram transferidas para solução nutritiva, $\mathrm{pH} 4,2$, na presença $0,296 \mathrm{mmol} \mathrm{L}^{-1}$ de Al, por um período de $20 \mathrm{~h}$. Nesta solução, Fe foi omitido, para evitar interferência no processo de coloração, e a concentração de $\mathrm{P}$ foi reduzida a 0,025 mmol L-1, para evitar precipitaçãocomalumínio.

O acúmul o de alumínio nas pontas das raízes foi avaliado pela col oração com hematoxilina, segundo método proposto por Polle et al. (1978), modificado quanto à concentração de hematoxilina. A solução 
Quadro 1. Identificação e origem dos genóti pos de café utilizados no experimento

\begin{tabular}{|c|c|c|}
\hline I dentificação & Origem do material & Variedade/híbrido \\
\hline UFV 2144 & IAC H 2077-2-5-44 & Catuaí Vermelho \\
\hline UFV 2145 & IAC H 2077-2-5-81 & Catuaí Vermelho \\
\hline UFV 2147 & IAC H 2077-2-5-99 & Catuaí Vermelho \\
\hline UFV 2237 & IAC H 2077-2-5-15 & Catuaí Vermelho \\
\hline UFV 2149 & IAC H 2077-2-12-91 & Catuaí Amarelo \\
\hline UFV 2150 & IAC LCMP 376-4-32 & Mundo Novo \\
\hline UFV 2163 & IAC LCP 388-17-16 & Mundo Novo \\
\hline UFV 2164 & IAC LCMP 515-3 & Mundo Novo \\
\hline UFV 1340 & UFV 386-19(1) & Catimor \\
\hline UFV 1603 & UFV 395-141(1) & Catimor \\
\hline UFV 2877 & 2 IV EP21.2 & Catimor \\
\hline UFV 2859 & 124 EP 20.1 & Catimor \\
\hline UFV 3869 & 202 EP 20.1 & Catimor \\
\hline UFV 3880 & 232 T15 PN & Catimor \\
\hline UFV 3092 & IAC 2942 & I catu Vermelho \\
\hline UFV 2953 & IAC 4040 & I catu Vermelho \\
\hline UFV 2954 & IAC 4042 & I catu Vermelho \\
\hline UFV 2955 & IAC 4045 & I catu Vermelho \\
\hline UFV 2956 & IAC 4782 & I catu Vermelho \\
\hline H 418-3 & UFV 2143-235 x UFV 443-01 & Catuaí Amarelo x Híbrido de Timor \\
\hline H 418-6 & UFV 2143-235 x UFV 443-01 & Catuaí Amarelo x Híbrido de Timor \\
\hline H 464-5 & UFV $2190-100$ x UFV $440-22$ & Mundo Novo x Híbrido de Timor \\
\hline H 484-2 & UFV 2164-193 x UFV 443-03 & Mundo Novo x Híbrido de Timor \\
\hline UFV 534 & CIFC 19/1 & Caturra Vermelho \\
\hline UFV 514 & Coffea canephora & Guarini \\
\hline
\end{tabular}

(1) Geração F $_{3}$ de CIFC HW26/5 (CIFC 19/1 - Caturra Vermelho x CIFC 832/1 - Híbrido de Timor).

corante foi preparada, dissolvendo-se $1 \mathrm{~g}$ de hematoxilina, $0,1 \mathrm{~g}$ de $\mathrm{NalO}_{3}$ e uma gota de $\mathrm{NaOH}$ 0,1 mol L-1 em um litro de água destilada.

O delineamento experimental utilizado foi em blocos casualizados, com três repetições e vinte e cinco tratamentos (genótipos). Cada bandeja com $30 \mathrm{~L}$ de solução nutritiva constituiu um bloco, com três plantas por parcela. Os resultados foram submetidos à análise de variância e as médias comparadas pelo teste de Scott-Knott, a 5\%, utilizando o programa SAEG - Sistema para análise estatística e genéticas (E uclydes, 1983).
Após o período de exposição ao Al, as plantas foram transferidas para bandejas que continham água desionizada e mantidas sob arejamento constante, por $30 \mathrm{~min}$. Em seguida, foram submetidas à solução de hematoxilina, por 15 min, em quantidade suficiente para cobrir as raízes, lavadas em água corrente por cerca de um minuto e, novamente, mantidas em água desionizada, por 3060 min, para remover o excesso de col oração. A ponta da raiz principal $(1,5 \mathrm{~cm})$ foi avaliada por meio de uma escala de notas que variou de 1 (menor acúmulo deAl) a 6 (maior acúmulo de Al) (Figura 1), conforme a intensidade e localização da região colorida,

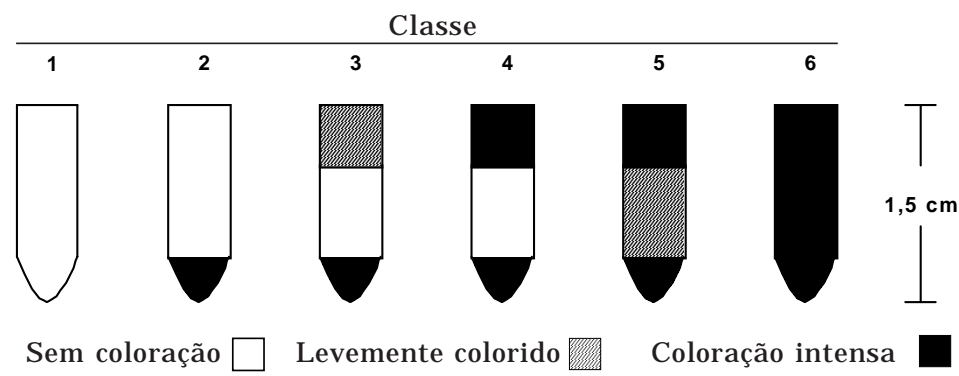

Figura 1. Avaliação do acúmulo de alumínio em raízes de plantas por meio do teste de coloração pela hematoxilina. 
segundo critério adotado por F onseca J r. (1982). As classes três e quatroapresentaram zonas deexclusão em virtude do acúmulo de Al na região basal nos genótipos mais tolerantes, enquanto os genótipos sensíveis apresentaram maior acúmulo de Al na região meristemática. As raízes foram examinadas por meio de microscópio esterioscópio Olympus model o SZH, com aumento de 10 vezes.

Para avaliar a alocação do Al nos tecidos radiculares, as plantas foram transferidas para solução nutritiva na presença de Al por $20 \mathrm{~h}$. Após este período, foram submetidas à col oração com hematoxilina, por $30 \mathrm{~min}$, e, posteriormente, mantidas em água desionizada por $10 \mathrm{~min}$. Em seguida, foram realizados cortes transversais das pontas das raízes $(0,5 \mathrm{~cm})$, examinados em microscópio Zeiss model o Docuval e, posteriormente, fotografados.

\section{RESULTADOS E DISCUSSÃO}

Enquanto na ausência de $\mathrm{Al}$ as raízes eram longas e finas e de col oração mais clara, na presença de Al apresentaram sintomas típicos de toxidez: engrossamento, amarel ecimento eencurtamento das raízes (Figura 2). Os sintomas detoxidez deAl observados neste trabal ho concordam com os relatados por Pavan \& Bingham (1982), Londoño \& ValenciaAristizábal (1983) e Rodrigues (1997).

Os efeitos tóxicos do Al no crescimento das plantas são atribuídos à sua influência sobre vários processos bioquímicos e fisiológicos (Marschner, 1995), sendo o crescimento radicular o principal indicador da sensibilidade das plantas à toxidez (Cambraia et al., 1991). O Al reduziu a produção de biomassa seca da parte aérea (BPA) e das raízes (BRA - Quadro 2), bem como a el ongação radicular (Quadro 3). Em alguns casos, ocorreu pequeno aumento na produção de biomassa seca da parte aérea das raízes, como constatado para os genótipos de I catu, UFV 2955 e 2956.

A el ongação radicular foi mais afetada do que a produção de biomassa seca da parte aérea e das raízes, apresentando redução de até $62 \%$ no caso do Guarini. A taxa de crescimento da raiz principal na ausência de $A$ I foi, em média, de $0,24 \mathrm{~cm}$ dia-1, enquanto na presença de Al reduziu-se para $0,16 \mathrm{~cm}$ dia-1, representando redução média na elongação radicular de 34\%. Macedo et al. (1997) também constataram que, na presença de $\mathrm{Al}$, o comprimento das raízes de quatro genóti pos de arroz foi mais afetado do quea produção de biomassa seca das raízes.

Nuernberg et al . (1990) ressaltarama importância de utilizar simultaneamente duas ou mais características, especialmenterelativas à parteaérea e raízes, para detectar diferenças na tolerância.

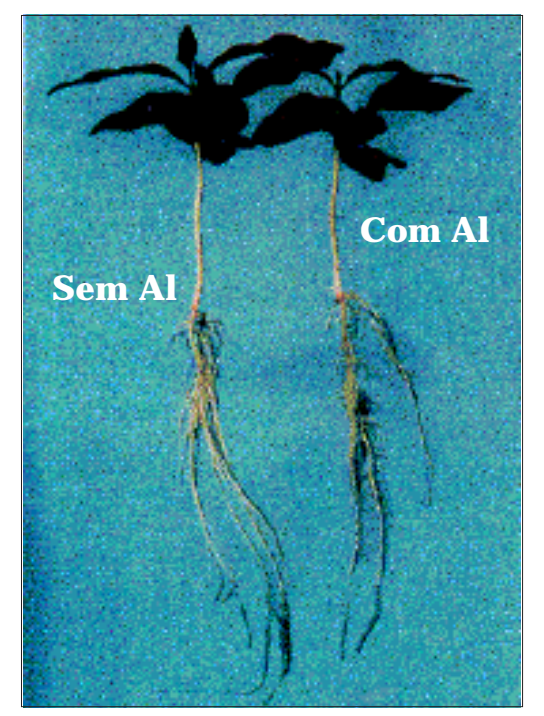

(a)

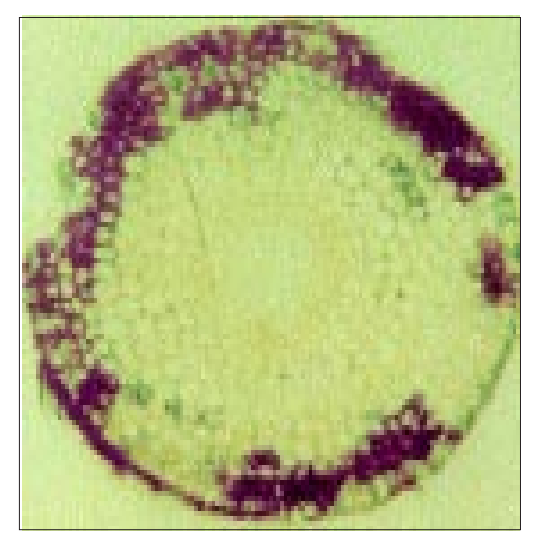

(b)

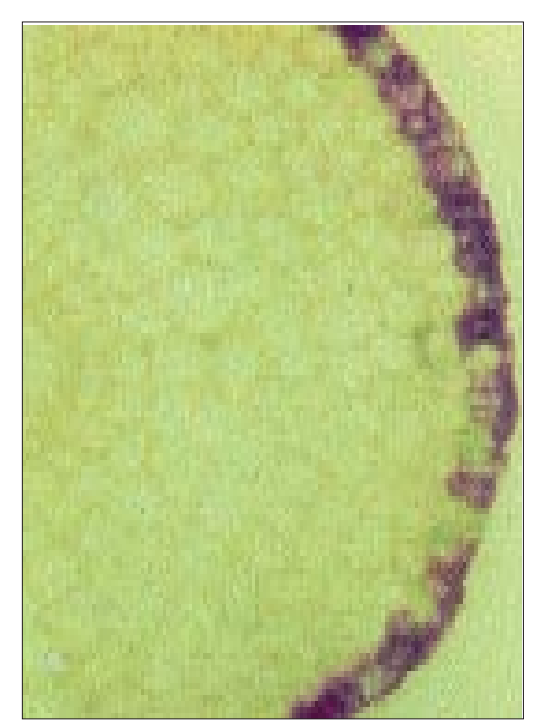

Figura 2. Desenvolvimento do sistema radicular do Robusta (UFV 514) na ausência e na presença de alumínio, em solução nutritiva, e cortes transversais da ponta de raízes de genótipos de café, após $20 \mathrm{~h}$ de exposição ao alumínio, na concentração de $0,296 \mathrm{mmol} \mathrm{L}^{-1}$, e coloridas com hemotoxilina. (a) tolerância intermediária (I catu, IC 4042) e (b) tolerante (I catu, IC 4045). 
Quadro 2. Produção de biomassa seca da parte aérea (BPA) e das raízes (BRA) e respectivos percentuais de variação de genótipos de café, em ausência e presença de alumínio em solução nutritiva

\begin{tabular}{|c|c|c|c|c|c|c|}
\hline \multirow{2}{*}{ Genótipo } & \multicolumn{3}{|c|}{ BPA } & \multicolumn{3}{|c|}{ BRA } \\
\hline & $-A \mid$ & $+\mathbf{A l}$ & Variação & $-\mathbf{A l}$ & $+\mathbf{A l}$ & Variação \\
\hline & \multicolumn{2}{|c|}{$\mathrm{mg}$} & $\%$ & \multicolumn{2}{|c|}{$\mathrm{mg}$} & $\%$ \\
\hline UFV 2144 & 90,83 & 62,58 & $-31,1$ & 25,83 & 20,42 & $-21,0$ \\
\hline UFV 2145 & 112,25 & 77,83 & $-30,7$ & 32,83 & 23,33 & $-28,9$ \\
\hline UFV 2147 & 110,58 & 90,18 & $-18,4$ & 40,75 & 29,17 & $-28,4$ \\
\hline UFV 2237 & 86,00 & 63,67 & $-26,0$ & 30,58 & 20,05 & $-34,4$ \\
\hline UFV 2149 & 101,08 & 87,25 & $-13,7$ & 32,25 & 25,75 & $-20,2$ \\
\hline UFV 2150 & 100,67 & 68,17 & $-32,3$ & 31,92 & 19,00 & $-40,5$ \\
\hline UFV 2163 & 84,75 & 64,17 & $-24,3$ & 24,08 & 18,00 & $-25,3$ \\
\hline UFV 2164 & 123,42 & 86,33 & $-30,0$ & 34,67 & 24,83 & $-28,4$ \\
\hline UFV 1340 & 124,00 & 73,67 & $-40,6$ & 34,54 & 17,42 & $-49,6$ \\
\hline UFV 1603 & 75,33 & 61,82 & $-17,9$ & 19,92 & 15,64 & $-21,5$ \\
\hline UFV 2877 & 87,92 & 53,36 & $-39,3$ & 27,50 & 13,00 & $-52,7$ \\
\hline UFV 2859 & 67,75 & 49,92 & $-26,3$ & 18,92 & 12,50 & $-33,9$ \\
\hline UFV 3869 & 132,33 & 97,58 & $-26,3$ & 36,83 & 25,75 & $-30,1$ \\
\hline UFV 3880 & 91,08 & 63,50 & $-40,2$ & 27,42 & 17,00 & $-37,0$ \\
\hline UFV 3092 & 90,25 & 74,67 & $-17,3$ & 23,42 & 19,17 & $-18,1$ \\
\hline UFV 2953 & 67,42 & 56,08 & $-16,8$ & 18,50 & 11,67 & $-36,9$ \\
\hline UFV 2954 & 77,00 & 57,00 & $-26,0$ & 17,25 & 11,70 & $-32,4$ \\
\hline UFV 2955 & 68,75 & 73,25 & $+6,55$ & 16,67 & 18,92 & $+13,5$ \\
\hline UFV 2956 & 61,08 & 61,75 & $+1,1$ & 14,17 & 14,58 & $+2,9$ \\
\hline H 418-3 & 82,50 & 69,67 & $-15,6$ & 19,67 & 15,00 & $-23,7$ \\
\hline H 418-6 & 82,58 & 68,58 & $-16,9$ & 23,75 & 18,42 & $-22,5$ \\
\hline H 464-5 & 91,67 & 61,75 & $-32,6$ & 23,50 & 12,50 & $-46,3$ \\
\hline H 484-2 & 80,36 & 57,25 & $-28,8$ & 18,91 & 15,17 & $-19,8$ \\
\hline UFV 534 & 123,17 & 79,83 & $-35,2$ & 39,25 & 24,17 & $-38,4$ \\
\hline UFV 514 & 138,33 & 94,58 & $-31,6$ & 40,25 & 27,58 & $-31,5$ \\
\hline Média & 94,04 & 70,51 & $-24,4$ & 26,78 & 19,07 & $-28,2$ \\
\hline
\end{tabular}

De acordo com Cambraia et al. (1991) e Macedo et al. (1997), os valores relativos são os melhores critérios para estimar a tolerância mesmo para amplitudes pequenas.

Foram obtidos para os genótipos tolerantes, sensíveis e detolerância intermediária, representados por $D_{t}(x), D_{s}(x)$ e $D_{i}(x)$, respectivamente, as seguintes funções discriminantes:

$$
\begin{aligned}
D_{t}(x)= & -6,4285+0,2415 \text { BPA }-0,3587 \text { BRA }+0,3386 \\
& \text { REDREL } \\
D_{i}(x)= & -4,7654+0,3995 \text { BPA - 0,3385 BRA +0,1855 } \\
& \text { REDREL } \\
D_{s}(x)= & -9,6231+0,3413 \text { BPA - 0,3556 BRA +0,3793 } \\
& \text { REDREL }
\end{aligned}
$$

A classificação dos genóti pos quanto à tolerância ao Al com as respectivas estimativas das funções discriminantes éapresentada no quadro 4. Verificaseque os genótipos considerados previamente como tolerante (UFV 2955), sensíveis (UFV 2877 e 3880) ou de tolerância intermediária (UFV 2145 e 2164) mantiveram suas posições com a análise discriminante. Desta forma, a taxa de erro aparente, que mede o número de classificação errada, foi nula. Portanto, as funções estimadas têm consistência estatística e as inferências a respeito dos genótipos desconhecidos são válidas.

O padrão de comparação da classe tolerante foi o UFV 2955. Este genótipo apresentou pequena redução na elongação radicular e aumento na produção de bi omassa seca da parteaérea edas raízes, na presença deAl. Desta forma, apenas três genótipos foram classificados como tolerantes, sendo dois I catu e um híbrido (Mundo Novo x Híbrido de Timor), enquanto seis foram classificados como sensíveis, sendo três Catimor, um I catu, um híbrido (Mundo Novo x Híbrido de Timor) e um Guarini (Quadro 4). O I catu é originário de cruzamento interespecífico 
Quadro 3. Comprimento da raiz principal aos 35 e 75 dias, taxa de crescimento de raiz (TCR) e redução relativa na elongação radicular (RE DREL) de genóti pos de café, em ausência e presença de alumínio em solução nutritiva

\begin{tabular}{|c|c|c|c|c|c|c|c|}
\hline \multirow{2}{*}{ Genótipo } & \multicolumn{3}{|c|}{ Sem Al } & \multicolumn{3}{|c|}{ Com Al } & \multirow[b]{2}{*}{ REDREL } \\
\hline & 35 dias & 75 dias & TCR & 35 dias & 75 dias & TCR & \\
\hline & \multicolumn{2}{|c|}{$-\mathrm{cm}$} & $\mathrm{cm} / \mathrm{dia}$ & \multicolumn{2}{|c|}{$\mathrm{cm}$} & $\mathrm{cm} / \mathrm{dia}$ & $\%$ \\
\hline UFV 2144 & 5,15 & 14,71 & 0,24 & 4,11 & 11,14 & 0,18 & 26,4 \\
\hline UFV 2145 & 5,51 & 14,57 & 0,23 & 5,17 & 11,91 & 0,17 & 25,6 \\
\hline UFV 2147 & 6,59 & 19,20 & 0,32 & 4,21 & 13,55 & 0,23 & 25,9 \\
\hline UFV 2237 & 5,08 & 14,56 & 0,24 & 3,67 & 10,05 & 0,16 & 32,7 \\
\hline UFV 2149 & 5,54 & 16,03 & 0,26 & 4,54 & 12,40 & 0,20 & 25,1 \\
\hline UFV 2150 & 4,69 & 15,49 & 0,27 & 7,54 & 15,03 & 0,19 & 30,6 \\
\hline UFV 2163 & 4,82 & 15,09 & 0,26 & 3,71 & 11,45 & 0,19 & 24,6 \\
\hline UFV 2164 & 7,33 & 19,33 & 0,30 & 2,99 & 11,72 & 0,22 & 27,2 \\
\hline UFV 1340 & 5,33 & 15,75 & 0,26 & 5,58 & 12,58 & 0,18 & 32,8 \\
\hline UFV 1603 & 6,67 & 16,05 & 0,23 & 3,94 & 11,31 & 0,18 & 21,4 \\
\hline UFV 2877 & 4,19 & 11,66 & 0,19 & 3,89 & 7,49 & 0,09 & 51,8 \\
\hline UFV 2859 & 4,95 & 16,10 & 0,28 & 3,37 & 9,03 & 0,14 & 49,2 \\
\hline UFV 3869 & 4,77 & 19,09 & 0,36 & 4,36 & 14,06 & 0,24 & 32,3 \\
\hline UFV 3880 & 5,61 & 19,01 & 0,34 & 3,61 & 10,22 & 0,17 & 50,7 \\
\hline UFV 3092 & 5,53 & 12,85 & 0,18 & 4,52 & 10,50 & 0,15 & 18,3 \\
\hline UFV 2953 & 5,37 & 12,11 & 0,17 & 5,04 & 7,74 & 0,07 & 59,9 \\
\hline UFV 2954 & 5,80 & 12,38 & 0,16 & 4,64 & 9,02 & 0,11 & 33,4 \\
\hline UFV 2955 & 8,50 & 16,05 & 0,19 & 6,61 & 12,51 & 0,15 & 21,8 \\
\hline UFV 2956 & 7,24 & 15,25 & 0,20 & 5,00 & 11,29 & 0,16 & 21,5 \\
\hline H 418-3 & 6,57 & 15,37 & 0,22 & 4,27 & 9,77 & 0,14 & 37,5 \\
\hline H 418-6 & 5,30 & 13,18 & 0,20 & 4,61 & 10,99 & 0,16 & 19,0 \\
\hline H 464-5 & 5,43 & 15,49 & 0,25 & 4,97 & 9,00 & 0,10 & 59,9 \\
\hline H 484-2 & 4,94 & 12,90 & 0,20 & 4,21 & 10,36 & 0,15 & 22,7 \\
\hline UFV 534 & 4,27 & 15,38 & 0,28 & 3,83 & 10,80 & 0,17 & 37,3 \\
\hline UFV 514 & 8,05 & 14,55 & 0,16 & 4,96 & 7,42 & 0,06 & 62,1 \\
\hline Média & 5,73 & 15,26 & & 4,53 & 10,85 & & 34,0 \\
\hline
\end{tabular}

entre Robusta e Bourbon Vermelho, o Catimor de cruzamento entre Caturra eHíbridoTimor, enquanto Híbrido de Timor é originário de hibridação espontânea entre C. canephora e C. arabica. Portanto, tanto os genótipos sensíveis quanto os tolerantes possuem como ancestrais a espécie Coffea canephora. Possivel mente, a maior sensibilidade ao Al se deve à contribuição do $C$. canephora, uma vez que o Guarini também foi sensível ao Al.

Passo \& Ruiz (1995) avaliaram a tolerância diferencial dos cafeeiros Conilon eCatuaí aos baixos índices de pH e aos teores el evados de Al em solução nutritiva. Em pH 4,0 e na presença de Al, após 170 dias do transplantio, o Conilon apresentou redução na produção de biomassa seca da parte aérea e das raízes de $80 \%$ e $75 \%$, respectivamente, enquanto o Catuaí mostrou redução de $67 \%$ na parte aérea e 58\% nas raízes. Esses resultados refor çama idéia de quea maior sensibilidadeapresentada pelos genótipos de Catimor, I catu e híbrido (Mundo Novo $\mathrm{x}$ Híbrido de Timor) deve-se à presença do $\mathrm{C}$. canephora na origem desses materiais.

Dezesseis genótipos apresentaram tolerância intermediária, dentre el es cinco Catuaí, três Mundo Novo, três Catimor, dois I catu, um Caturra e dois híbridos (Catuaí x Híbrido de Timor; Mundo N ovox Híbrido de Timor) (Quadro 4).

Bragança et al. (1987) avaliaram o comportamento de dois cultivares de café, um Catimor e um Catuaí Amarelo, sob níveis crescentes de Al trocável no solo, durante seis meses. Os dois cultivares não apresentaram tolerância ao Al e foram afetados de modo semel hante, apresentando redução na produção de biomassa seca de folhas, caule e raízes, altura de plantas, diâmetro de cauleeárea foliar. Na presença de $2,0 \mathrm{cmol}_{\mathrm{c}} \mathrm{dm}^{-3}$ de $\mathrm{Al} 3+$, a redução na produção de biomassa seca das raízes foi de $47 \%$, para o Catimor, ede $80 \%$, para o Catuaí. Dos seis genótipos deCatimor, 
Quadro 4. Classificação dos genótipos de café quanto à tolerância ao alumínio, com as respectivas estimativas das funções discriminantes, considerando o percentual de variação na produção de biomassa seca da parte aérea e das raízes e redução relativa na elongação radicular

\begin{tabular}{|c|c|c|c|c|}
\hline Genótipo & $\operatorname{Dt}(x)$ & $\operatorname{Di}(x)$ & $\operatorname{Ds}(x)$ & Classificação \\
\hline UFV 2144 & 2,5044 & 5,4617 & 3,5551 & Intermediária \\
\hline UFV 2145 & $-0,7321$ & 2,4400 & 0,2660 & Intermediária \\
\hline UFV 2147 & $-3,3883$ & $-2,2064$ & $-3,5982$ & Intermediária \\
\hline UFV 2237 & $-1,4343$ & 0,0211 & $-0,5953$ & Intermediária \\
\hline UFV 2149 & $-1,8650$ & $-1,4722$ & $-2,6113$ & Intermediária \\
\hline UFV 2150 & $-2,7712$ & 0,1188 & $-1,3707$ & Intermediária \\
\hline UFV 2163 & $-1,2944$ & 0,9503 & $-0,9850$ & Intermediária \\
\hline UFV 2164 & $-0,1199$ & 2,6920 & 0,8820 & Intermediária \\
\hline UFV 1340 & $-3,3036$ & 0,7531 & $-0,9581$ & Intermediária \\
\hline UFV 1603 & $-2,5488$ & $-0,8979$ & $-3,0140$ & Intermediária \\
\hline UFV 2877 & 1,6920 & 2,6981 & 4,6921 & Sensível \\
\hline UFV 2859 & 4,4335 & 3,4012 & 5,9756 & Sensível \\
\hline UFV 3869 & 0,0442 & 1,5245 & 0,8772 & Intermediária \\
\hline UFV 3880 & 7,1609 & 8,1710 & 10,1604 & Sensível \\
\hline UFV 3092 & $-2,5701$ & $-0,6148$ & $-3,2398$ & Intermediária \\
\hline UFV 2953 & 4,6795 & 0,5655 & 5,7166 & Sensível \\
\hline UFV 2954 & $-0,4500$ & 0,8565 & 0,4118 & Intermediária \\
\hline UFV 2955 & 4,2339 & 1,2422 & 1,2345 & Tolerante \\
\hline UFV 2956 & 1,6343 & $-0,2235$ & $-0,8038$ & Tolerante \\
\hline H 418-3 & 1,5149 & 0,3727 & 1,4728 & Tolerante \\
\hline H 418-6 & $-3,9437$ & $-2,0627$ & $-4,6019$ & Intermediária \\
\hline H 464-5 & 5,1361 & 3,7132 & 7,7822 & Sensível \\
\hline H 484-2 & 1,1171 & 4,2434 & 1,7809 & Intermediária \\
\hline UFV 534 & 0,9014 & 3,1948 & 2,8546 & Intermediária \\
\hline UFV 514 & 10,9674 & 8,7457 & 13,5578 & Sensível \\
\hline
\end{tabular}

avaliados no presente trabalho, três foram considerados sensíveis e três apresentaram tolerância intermediária.

O teste de coloração com hematoxilina possi bilitou separar pelo testeScott-K nott apenas o genótipo que acumulou mais Al, o I catu 4042 (Grupo I) dos demais (Grupo II). Ele apresentou maior intensidade de col oração nas pontas das raízes, recebendo nota 6 , enquanto os outros apresentaram, em média, nota 2,24, uma vez que pertenceram às classes 2 e 3 . As plantas foram expostas ao Al, na concentração de 0,296 mmol L-1, durante 20 h. Esta condição não permitiu adequada diferenciação dos genótipos. Desta forma, para a melhor utilização deste método, torna-se necessário estabelecer anteriormente a concentração, bem como o tempo de exposição ao Al.

A coloração com hematoxilina, isoladamente, não é considerada adequada para sel eção de genótipos de café tolerantes ao Al, porque o resultado obtido depende dos mecanismos de tolerância envolvidos. Por exemplo, um genótipo que acumule muito Al e apresente mecanismo detolerância relacionado com a detoxificação do $\mathrm{Al}$ após sua absorção poderá ser considerado sensível peloteste. Por outrolado, Polle et al . (1978), Wallace et al. (1982) eScott et al. (1992) utilizaram o teste de coloração com hematoxilina para selecionar genótipos de trigo quanto à tolerância aoAl. Esses pesquisadores concluíram que é um teste simples e rápido para separar grande número de populações e que se correlacionou bem com os resultados obtidos em solução nutritiva. Todavia, tal comportamento não parece ser verdadeiro para cultivares de feijão (Massot et al., 1991) e para genótipos de café.

Cultivares de trigo tolerantes ao Al possuem menor capacidade de troca de cátions das raízes e tendem a acumular menos Al (Polle et al., 1978). Desta forma, o teste de col oração com hematoxilina poderia indicar maior ou menor tolerância ao Al. Por outrolado, em feijão, Massot et al. (1991) verificaram quea maior tolerância ao Al foi relacionada com alta concentração de $\mathrm{Al}$ nas raízes. Este acúmulo de $\mathrm{Al}$ nas variedades tolerantes pode ser explicado pela mai or capacidade de preci pitar oAl como polímeros, excluindo o Al da membrana plasmática (Taylor, 1991; Kochian, 1995).

E $m$ raízes de café expostas ao Al durante $20 \mathrm{~h}$, observou-se que, no genótipo mais tolerante (Figura 2b), o Al localizou-se apenas nas células 
epidérmicas, enquanto, no genótipo de tolerância intermediária (Figura 2a), observou-se sua presença nas células epidérmicas e em várias camadas de células do córtex. Nenhuma col oração foi observada nas raízes das plantas-controle (sem Al), seccionadas e examinadas ao microscópio. Rincón \& Gonzales (1992) verificaram que a sensibilidade diferencial de cultivares de trigo pode ocorrer em virtude da alocação de Al na região meristemática. O cultivar sensível apresenta maior intensidade de coloração na região apical, enquanto o cultivar tolerante mostra al ocação de Al na região basal. Observaram, também, que o Al localizou-se principalmente na paredecelular, nos espaços intercelulares eno núcleo das células do córtex e da epiderme.

A menor formação do complexo Al-hematoxilina, no caso do genóti po tolerante UFV 2955, pode estar relacionada com mudanças químicas ocorridas nas pontas das raízes, tais como: alterações no pH próximo às raízes ou síntese de quelatos que podem interferir na formação do compl exo Al-hematoxilina (Massot et al., 1991; Kochian, 1995). A localização do Al nos tecidos radiculares, avaliada por meio de cortes transversais na ponta da raiz colorida, associada com outras características, como redução no crescimento radicular, permite inferir estar a maior tolerância apresentada pel o I catu (UFV 2955) relacionada com algum mecanismo de exclusão.

\section{CONCLUSÕES}

1. De acordo com a variação percentual na produção de biomassa seca de parte aérea e raízes, e a redução relativa na el ongação radicular, vinte e cinco genótipos de café foram agrupados em três classes detolerância ao Al. Dezesseis apresentaram tolerância intermediária, seis foram classificados como sensíveis e apenas três foram tolerantes ao Al na concentração de 0,296 mmol L-1.

2. O teste de coloração com hematoxilina não se caracterizou como um método de discriminação promissor para selecionar genótipos de café quanto à tolerância ao Al.

3. Em genóti po com tolerância intermediária, que apresentou maior intensidade de coloração com hematoxilina, o Al localizou-se nas células epidérmicas e em várias camadas de células do córtex. Em genótipo mais tolerante, o Al Iocalizouse apenas nas células epidérmicas, evidenciando a existência de mecanismo de exclusão.

\section{LITERATURA CITADA}

ANDERSON, T.W. An introduction to multivariate statistical analysis. New York, J ohn Wiley, \& Sans, 1958. 374p.
BRACCINI, M.C.L.; BRACCINI, A.L.; MARTINEZ, H.E.P.; PEREIRA, P.R.G. \& FONTES, P.C.R. Técnicas deavaliação da toxidez do alumínio em plântulas de feijão (Phaseolus vulgaris L). cultivadas em solução nutritiva. R. Ceres, 43 : 3-16, 1996.

BRACCINI, M.C.L.; MARTINEZ, H.E.P.; PEREIRA, P.R.G.; SAMPAIO, N.F. \& SILVA, E.A.M. Tolerância de genótipos de cafeei ro ao alumínio em solução nutritiva . I . crescimento e desenvolvimento da parte aérea e sistema radicular. R. Bras. Ci. Solo, 22:435-442, 1998.

BRAGANÇA, J .B.; PAULINO, A.J .; MATIELLO, J .B. \& FABRIS, E.J . Efeito do alumínio trocável do solo sobre o crescimento inicial do cafeei ro (Coffea arabica L.) catimor (Catimor 183) ecatuaí. In: CONGRESSO BRASILEIRO DE PESQUISAS CAFEEIRAS, 14., Campinas, 1987. Anais. Rio de J aneiro, COTEC/DIPRO/IBC, 1987. p. 295-297.

CAMBRAIA, J .; SILVA, M.A.; CANO, M.A.O. \& SANT'ANNA, R. Método simples para a avaliação de cultivares de sorgo quanto a tolerância ao alumínio. R. Bras. Fisiol. Veg., 3:8795, 1991.

CHAVES, J .C.D.; PAVAN, M.A. \& MIYAZAWA, M. Redução da acidez subsuperficial em coluna de solo. Pesq. Agropec. Bras., 23:469-476, 1988.

CRUZ, C.D. Programa GENES - aplicativo computacional em genética e estatística. Viçosa, Universidade Federal de Viçosa, 1997. 442p.

EUCLYDES, R.F. Sistema para análise estatística e genéticas (SAEG) - manual provisório. Viçosa, Universidade Federal de Viçosa, 1983. 74p.

FONSECA J r., N.S. Estudo da herança da tolerância ao alumínio em soja (Glycine max (L.) Merrill), pelo método da hematoxilina. Viçosa, UniversidadeFederal deViçosa, 1982. 46p. (Tese de Mestrado)

FOY, C.D. Tolerance of eastern gamagrass to excess of aluminum in acid soil and nutrient solution. J. Plant Nutr., 20:11191136, 1997.

GUIMARÃES, P.T.G. O uso do gesso agrícola na cultura do cafeeiro. In: SEMINÁRIO SOBRE O USO DO GESSO NA AGRICULTURA, 2., Uberaba, 1992. Anais. São Paulo, Instituto Brasileiro do Fosfato, 1992. p.175-190.

HOAGLAND, D.R. \& ARNON, D.I. The water-culture method for growing plants without soil. Berkeley, Cal. Agric. Exp. Station, 1950. 347p. (Cal. Agric. Exp. Station, Cir.)

KOCHIAN, L.V. Cellular mechanisms of aluminum toxicity and resistance in plants. Ann. Rev. Plant Physiol. Plant Mol. Biol., 46:237-260, 1995.

LONDOÑO, M.E.A. \& VALENCIA-ARISTIZÁBAL, G. Toxicidade de aluminuio en plantas de café. Cenicafé, 34:61-97, 1983.

MACEDO, J . Os solos da região dos cerrados. In: ALVAREZ V., V.H.; FONTES, L.E.F. \& FONTES, M.P.F., eds. O solo nos grandes domínios morfoclimáticos do Brasil e o desenvolvimento sustentado. Viçosa, Sociedade Brasileira de Ciência do Solo, 1996. p.135-140. 
MACEDO, C.C.; KINET, J.M. \& Van SINT J AN, V. Effects of duration and intensity of aluminum stress on growth parameters in four genotypes differing in aluminum sensitivity. J . Plant Nutr., 20:181-193, 1997.

MARSCHNER, H. Mineral nutrition of higher plants. London, Academic Press, 1995. 889p.

MASSOT, N.; POSCHENRIEDER, C. \& BARCELÓ, J . Aluminum tolerance assessment in bush bean cultivars by root growth analysis and hematoxylin staining. Suelo Planta, 1:25-32, 1991.

MIX, G. Application of in vitro techniques for screening plant genetic variability. In: EL BASSAM, N.; DAMBROTH, M. \& LOUGHMAN, B.C., eds. Genetic of plant mineral nutrition. Netherlands, Kluwer Academic Publishers, 1990. p.339-343.

NUERNBERG, N.J .; BISSANI, C.A.; CAMPBELL, T.A. \& FOY, C.D. Screening pasture plants for aluminum tolerance. In: EL BASSAM, N.; DAMBROTH, M. \& LOUGHMAN, B.C., eds. Genetic of plant mineral nutrition. Netherlands, Kluwer Academic Publishers, 1990. p.345-353.

PASSO, R.R. \& RUIZ, H.A. Tolerância dos cafeeiros conilon e catuaí à toxidez causada pelo alumínio e manganês. R. Ceres, 42:45-52, 1995.
PAVAN, M.A. \& BINGHAM, F.T. Toxicity of aluminum to coffee grown in nutrient solution. Soil Sci. Soc. Am. J., 46:993997, 1982.

POLLE, E.; KONZAK, C.F.\& KITTRICK, J .A. Visual detection of aluminum tolerancelevels in wheat by hematoxilin staining of seeedling roots. Crop Sci., 18:823-827, 1978.

RINCÓN, M. \& GONZALES, R.A. Aluminum partitioning in intact roots of aluminum-tolerant and aluminum-sensitive wheat (Triticum aestivum L.) cultivars. Plant Physiol., 99:1021-1028, 1992.

RODRIGUES, L.A. Crescimento e composição mineral na parte aérea e raízes de duas variedades de café em resposta à calagem na subsuperfície do solo. Viçosa, Universidade Federal de Viçosa, 1997. 89p. (Tese de Mestrado)

SCOTT, B.J .; FISHER, J .A. \& SPOHR, J . Tolerance of Australian wheat varieties to aluminum toxicity. Comm. Soil Sci. Plant Anal., 23:509-526, 1992.

TAYLOR, G.J . Current views of the aluminum stress response; the physiological basis of tolerance. Cur. Top. Plant Biochem. Physiol., 10:57-93, 1991.

WALLACE, S.U.; HENNING, S.J . \& ANDERSON, I.C. Elongation, Al concentration, and hematoxylin staining of aluminumtreated wheat roots. I owa State J . Res., 57:97-106, 1982. 